\title{
Cerebellar Neurons Possess a Vesicular Compartment Structurally and Functionally Similar to Glut4-Storage Vesicles from Peripheral Insulin-Sensitive Tissues
}

\author{
Kyriaki Bakirtzi, ${ }^{1}$ Gabriel Belfort, ${ }^{1}$ Ignacio Lopez-Coviella, ${ }^{2}$ Darshini Kuruppu, ${ }^{3}$ Lei Cao, ${ }^{3}$ E. Dale Abel, ${ }^{4}$ \\ Anna-Liisa Brownell, ${ }^{3}$ and Konstantin V. Kandror ${ }^{1}$ \\ Departments of ${ }^{1}$ Biochemistry and ${ }^{2}$ Psychiatry, Boston University School of Medicine, Boston, Massachusetts 02118, ${ }^{3}$ Massachusetts General Hospital, \\ Boston, Massachusetts 02114, and ${ }^{4}$ Division of Endocrinology, Metabolism, and Diabetes and the Program in Human Molecular Biology and Genetics, \\ University of Utah, Salt Lake City, Utah 84112
}

The insulin-sensitive isoform of the glucose transporting protein, Glut4, is expressed in fat as well as in skeletal and cardiac muscle and is responsible for the effect of insulin on blood glucose clearance. Recent studies have revealed that Glut 4 is also expressed in the brain, although the intracellular compartmentalization and regulation of Glut4 in neurons remains unknown. Using sucrose gradient centrifugation, immunoadsorption and immunofluorescence staining, we have shown that Glut4 in the cerebellum is localized in intracellular vesicles that have the sedimentation coefficient, the buoyant density, and the protein composition similar to the insulin-responsive Glut4-storage vesicles from fat and skeletal muscle cells. In cultured cerebellar neurons, insulin stimulates glucose uptake and causes translocation of Glut4 to the cell surface. Using ${ }^{18} \mathrm{FDG}\left({ }^{18}\right.$ fluoro-2-deoxyglucose) positron emission tomography, we found that physical exercise acutely increases glucose uptake in the cerebellum in vivo. Prolonged physical exercise increases expression of the Glut 4 protein in the cerebellum. Our results suggest that neurons have a novel type of translocation-competent vesicular compartment which is regulated by insulin and physical exercise similar to Glut4-storage vesicles in peripheral insulin target tissues.

\section{Introduction}

Glut4 is the insulin-responsive isoform of the glucose transporter protein which is responsible for postprandial glucose clearance (Huang and Czech, 2007) and, more generally, for glucose sensing and metabolic homeostasis in the body (Herman and Kahn, 2006). Traditionally, it is believed that Glut 4 is expressed only in skeletal muscle, cardiac muscle and fat, i.e., in tissues that represent major physiological sinks for circulating glucose. In these tissues, $50-75 \%$ of total Glut 4 is localized in specialized trafficking organelles, GSVs (for Glut4-storage vesicles), that deliver Glut4 to the plasma membrane in response to insulin stimulation (Huang and Czech, 2007) and, in the case of myocytes, exercise (Rose and Richter, 2005). In addition to Glut4, the GSVs include two major cargo proteins, insulin-responsive aminopeptidase, or IRAP (Kandror et al., 1994; Keller et al., 1995) and a putative sorting receptor sortilin (Lin et al., 1997; Morris et al., 1998) as well as the v-SNARE, VAMP2 (Cain et al., 1992), SCAMPs (Laurie et al., 1993; Thoidis et al., 1993) and several recycling receptors

Received Feb. 19, 2009; accepted March 11, 2009.

This work was supported by research grants from the National Institutes of Health [Grants EB001850 (A.L.B.) and DK52057 and DK56736 (K.V.K.)], and by an Innovation Award from the American Diabetes Association (K.V.K.). We are grateful to Dr. Paul Toselli, Dr. Daniela Pellegrino, Dr. Aijun Zhu, and Mark Jedrychowski for help with some experiments.

Correspondence should be addressed to Konstantin V. Kandror, Boston University School of Medicine, Department of Biochemistry, K124D, 715 Albany Street, Boston, MA 02118. E-mail: kandror@biochem.bumc.bu.edu DOI:10.1523/JNEUROSCI.0858-09.2009

Copyright $\odot 2009$ Society for Neuroscience $\quad$ 0270-6474/09/295193-09\$15.00/0 and other membrane proteins that may or may not represent essential vesicular components (Larance et al., 2005).

Interestingly, recent studies have demonstrated that all the known component proteins of the GSVs including IRAP, sortilin and even Glut4, are expressed in the brain at significant levels (Rayner et al., 1994; Kobayashi et al., 1996; Leloup et al., 1996; McCall et al., 1997; El Messari et al., 1998; Mazella et al., 1998; Vannucci et al., 1998; Apelt et al., 1999; Alquier et al., 2001; Choeiri et al., 2002; Lu et al., 2004; Fernando et al., 2005, 2008; Komori et al., 2005). Although multiple neurons in forebrain, cerebral cortex and hippocampus are known to be Glut4positive, studies agree that areas involved in the regulation of metabolism (hypothalamic nuclei) and motor activity (sensorimotor cortex, motor nuclei of cranial nerves, motor neurons of the ventral horn of the spinal cord and, specially, cerebellum) are the regions with the highest Glut 4 content (for review, see Routh, 2002; McEwen and Reagan, 2004).

Vast majority of the published studies address only the total expression levels of Glut 4 and/or cognate mRNA in various brain regions, so that the intracellular localization of Glut4 in neurons remains largely unknown. To the best of our knowledge, only one group has described the subcellular localization of Glut4 in neuronal cells (El Messari et al., 1998), and another group has studied IRAP (Fernando et al., 2005, 2007, 2008). Using light and electron microscopy, these authors found that, under basal conditions, both proteins are localized not in the plasma membrane but inside the cell with a significant fraction of the total neuronal Glut 4 and IRAP pools being present in small clear vesicles remi- 
niscent of those present in basal adipocytes and myocytes (Smith et al., 1991; Ploug et al., 1998). However, it is still not known whether neuronal Glut4 and IRAP are localized in the same or in different vesicles and whether or not these vesicles translocate to the cell surface. Thus, the protein composition and functions of neuronal Glut4-vesicles remain unknown and it is not yet clear whether or not Glut4 actually participates in glucose uptake in neurons.

Here, we confirm that certain brain areas, such as the cerebellum, endogenously express high levels of Glut4, and that Glut4 in the cerebellar neurons is localized in intracellular vesicles that are different from small synaptic vesicles (SSVs) but have the sedimentation coefficient, the buoyant density and the protein composition similar to the GSVs from fat and skeletal muscle cells. We also show that neuronal Glut4-vesicles are translocated to the plasma membrane in response to insulin stimulation and exercise.

\section{Materials and Methods}

Antibodies. Monoclonal antibody against Glut4 (1F8) and a polyclonal antibody against IRAP were a kind gift from Dr. Paul Pilch (Boston University School of Medicine, Boston, MA). Polyclonal antibody against Glut4 MC2A was a kind gift from Dr. Giulia Baldini (University of Arkansas, Pine Bluff, AR) and polyclonal antibody against Glut $4 \alpha \mathrm{G} 4$ was a kind gift from Dr. Samuel Cushman (National Institute of Diabetes and Digestive and Kidney Diseases, Bethesda, MD). Another polyclonal antibody against Glut4, C-20, was purchased from Santa Cruz (Santa Cruz, CA). Monoclonal antibodies against synaptophysin was from Millipore Bioscience Research Reagents, against VAMP2, from Synaptic Systems, and against sortilin, from BD Biosciences PharMingen.

Mouse tissue homogenization and fractionation. CD-1 mice and Sprague Dawley rats were killed by $\mathrm{CO}_{2}$ inhalation followed by cervical dislocation under an approved IACUC protocol. Gastrocnemius muscle and cerebellum were isolated and homogenized in Buffer A $(150 \mathrm{~mm}$ $\mathrm{NaCl}, 10 \mathrm{~mm}$ HEPES, pH7.4, $1 \mathrm{~mm}$ EGTA, $0.1 \mathrm{~mm} \mathrm{MgCl}_{2}$ ) with protease inhibitors $(1 \mu \mathrm{M}$ aprotinin, $5 \mathrm{~mm}$ benzamidine, $2 \mu \mathrm{M}$ leupeptin, $1 \mu \mathrm{M}$ pepstatin, $1 \mathrm{~mm}$ phenylmethylsulfonyl fluoride) using a ball bearing cell cracker (European Molecular Biology Laboratory, Heidelberg, Germany). Homogenates were centrifuged at $1000 \times g$ for 5 min to generate a postnuclear supernatant (PNS) that was further centrifuged at $27,000 \times g$ for $35 \mathrm{~min}$ in a Ti42.2 rotor (Beckman Coulter) to produce high-speed supernatant (S2) and the heavy membrane pellet P1. For velocity gradient centrifugation, $1 \mathrm{mg}$ of $\mathrm{S} 2$, adjusted to the volume of $300 \mu \mathrm{l}$, was layered on a $4.6 \mathrm{ml}$ linear $10-30 \%(\mathrm{w} / \mathrm{v})$ sucrose gradient in Buffer A. Gradients were centrifuged at $280,000 \times g$ for $1 \mathrm{~h}$ in a SW55 rotor (Beckman Coulter). For the equilibrium density gradient centrifugation, $1 \mathrm{mg}$ of S2, adjusted to the volume of $300 \mu \mathrm{l}$, was layered onto a $4.6 \mathrm{ml} 10-50 \%(\mathrm{w} / \mathrm{v})$ continuous sucrose gradient in Buffer A. Centrifugation was performed at $280,000 \times g$ for $16 \mathrm{~h}$ in a SW55 rotor (Beckman Coulter). Fractions were collected from the bottom of the tube using a peristaltic pump.

For the isolation of the plasma membrane fraction, P1 was resuspended in $2 \mathrm{ml}$ of Buffer A, layered on top of $3 \mathrm{ml}$ of $1.12 \mathrm{M}$ sucrose solution in Buffer A, and centrifuged at 116,000 $\times g(31,000 \mathrm{rpm})$ for $1 \mathrm{~h}$ in a SW55 rotor (Beckman Coulter). Material at the interface was collected, brought up to $4 \mathrm{ml}$ with Buffer A and pelleted by centrifugation at $42,000 \times g(22,000 \mathrm{rpm})$ for $20 \mathrm{~min}$ in a Ti70 rotor (Beckman Coulter). The plasma membrane pellet was resuspended in 250-500 $\mu$ l of Buffer A.

Immunoprecipitation. Affinity purified $1 \mathrm{~F} 8$ antibody and control mouse IgG (Sigma) were each coupled to Dynal magnetic beads at a concentration of $2 \mu \mathrm{g}$ of antibody per $30 \mu \mathrm{l}$ of beads according to manufacturer's instructions. Before use, the antibody-coupled beads were blocked with $1 \% \mathrm{BSA}$ in PBS for $30 \mathrm{~min}$ at $4^{\circ} \mathrm{C}$, followed by wash with PBS. Triton X-100 and $\mathrm{NaCl}$ were added to $\mathrm{S} 2$ obtained from adult $\mathrm{CD}-1$ mouse cerebellum to final concentrations $1 \%$ and $0.5 \mathrm{M}$ respectively, and this material (typically, $1 \mathrm{mg}$ ) was incubated with $30 \mu \mathrm{l}$ of $1 \mathrm{~F} 8$ - and nonspecific IgG-coated beads overnight at $4^{\circ} \mathrm{C}$. Beads were then washed with 1\% Triton X-100 in PBS and eluted with Laemmli sample buffer for $1 \mathrm{~h}$ at room temperature. Eluates were subjected to SDS-PAGE.

Immunoadsorption. $1 \mathrm{~F} 8$ and IgG were coupled to Dynal magnetic beads as described in the previous section. S2 obtained from adult CD-1 mouse cerebellum (typically, $1 \mathrm{mg}$ ) containing $0.5 \mathrm{M} \mathrm{NaCl}$, was incubated with $30 \mu \mathrm{l}$ of $1 \mathrm{~F} 8$ - and nonspecific IgG-coated beads overnight at $4^{\circ} \mathrm{C}$. Beads were then washed with PBS and eluted with $1 \%$ Triton X-100 in PBS for $1 \mathrm{~h}$ at $4^{\circ} \mathrm{C}$. After Triton elution, beads were eluted with Laemmli sample buffer for $1 \mathrm{~h}$ at room temperature. Eluates were subjected to SDS-PAGE.

Primary cell culture. Seven-day-old CD-1 mice were killed by decapitation and brains were isolated in ice-cold Hibernate-A medium (BrainBits). Cerebellums were gently removed, cut into small pieces and digested in Hibernate-A medium containing $20 \mathrm{U} / \mathrm{ml}$ papain and $250 \mathrm{U} / \mathrm{ml}$ DNase (Worthington Biochemical). Digestion was stopped by washing the tissues with the solution consisting of Hibernate-A media, $1 \mathrm{mg} / \mathrm{ml}$ ovomucoid albumin inhibitor and $125 \mathrm{U} / \mathrm{ml}$ DNase. Cerebellar cells were gently dissociated using borosilicate fire-polished siliconized glass pipettes. The cell suspension was layered on top of $4 \%$ BSA Hibernate-A and centrifuged at $2000 \times g$ for 4 min after which the centrifugal force was decreased to $1000 \times g$ and centrifugation continued in the same tubes for another $4 \mathrm{~min}$. A loose pellet of isolated cells was resuspended in the Basal Eagle Medium (Sigma-Aldrich) containing 10\% horse serum and $1 \%$ penicillin/streptomycin, and plated on poly-D-lysine-coated culture dishes or coverslips. After $24 \mathrm{~h}$, the medium was replaced with the Neurobasal/B27, 1\% penicillin/streptomycin, 2 mm L-Glutamine and 0.5 mu GlutaMAX (all from Invitrogen). Cells were cultured for $7 \mathrm{~d}$ at $37^{\circ} \mathrm{C}$, $5 \% \mathrm{CO}_{2}$.

$R T$-PCR. Total RNA (3-4 $\mu \mathrm{g})$ was isolated from mouse cerebella or from primary cerebellar neurons using the TRIzol reagent (Invitrogen). Total RNA was reverse transcribed into cDNA with the help of M-MLV reverse transcriptase (Invitrogen). cDNA was amplified by PCR using the sense primer CCCTGTTACCTCCAGGTTGA and the antisense primer AGAGCCTGTGTGGCAAGAGT, and the PCR product was subjected to the agarose gel electrophoresis.

${ }^{3} \mathrm{H}$-2-Deoxy-D-glucose uptake. Primary neurons were plated on $60 \mathrm{~mm}$ culture dishes and transferred to serum-free DMEM for $4 \mathrm{~h}$ before each experiment. Indinavir (100 nM, Merck), wortmannin (100 nM) and cytochalasin B ( $5 \mathrm{~mm}$ ) (both from Sigma) were added 30 min before the experiments. Plates were washed with glucose-free $\mathrm{KRH}$ medium (121 mм NaCl, 4.9 mм KCl, 1.2 mм $\mathrm{MgSO}_{4}, 0.33 \mathrm{~mm} \mathrm{CaCl}_{2}, 12 \mathrm{~mm}$ HEPES acid, $\mathrm{pH}$ 7.4) and treated with $100 \mathrm{~nm}$ insulin (Sigma) or carrier for 15 min. ${ }^{3} \mathrm{H}$-2-Deoxy-D-glucose/2-deoxy-D-glucose mixture (specific activity: $6.25 \mathrm{mCi} / \mathrm{mmol}$ ) was added for $3.5 \mathrm{~min}$ at $37^{\circ} \mathrm{C}$. Glucose uptake was stopped by washing plates with ice-cold $\mathrm{KRH}$ with $25 \mathrm{~mm}$ glucose and 10 $\mu \mathrm{M}$ cytochalasin B for 3 times. Cells were then collected in glucose-free $\mathrm{KRH}$ with $0.1 \%$ SDS, and radioactivity was counted by liquid scintillography in EcoLume (ICN Biomedicals).

Immunohistochemistry. Mouse brains were isolated and fixed for 30 $\min$ in $4 \%$ paraformaldehyde. Fixed tissue was dehydrated and embedded in Paraplast (Oxford Labware). Sections $(4-5 \mu \mathrm{m})$ were obtained with the help of a Microtome No820 (American Optical) and mounted on Superfrost/Plus microscope slides (Fisher Scientific). Sections were deparaffinized, rehydrated and treated with antigen unmasking solution according to manufacturer's instructions (Vector Laboratories) and permeabilized with $0.2 \%$ Triton X100 in PBS. Sections were blocked with MOM mouse IgG blocking reagent (Vector Laboratories), washed with Gadenza buffer (Vector Laboratories) and stained with polyclonal antiGlut4 antibody MC2A followed by Cy3-conjugated goat anti-rabbit IgG (Jackson ImmunoResearch Laboratories). Coverslips were mounted on sections using the Slow Fade-Light Antifade kit (Invitrogen) and immunofluorescence was examined by fluorescence microscopy (Axiovert 200M; Carl Zeiss).

Immunofluorescence staining. Primary neurons grown on poly-Dlysine-coated coverslips were fixed with $4 \%$ paraformaldehyde, permeabilized with $0.2 \%$ Triton X-100, blocked with $4 \%$ donkey serum and probed with primary antibodies followed by Cy3-conjugated rabbit antimouse IgG (Jackson ImmunoResearch), Alexa 488-conjugated donkey anti-rabbit IgG, Cy3-conjugated donkey anti-mouse IgG (Invitrogen) or 
A
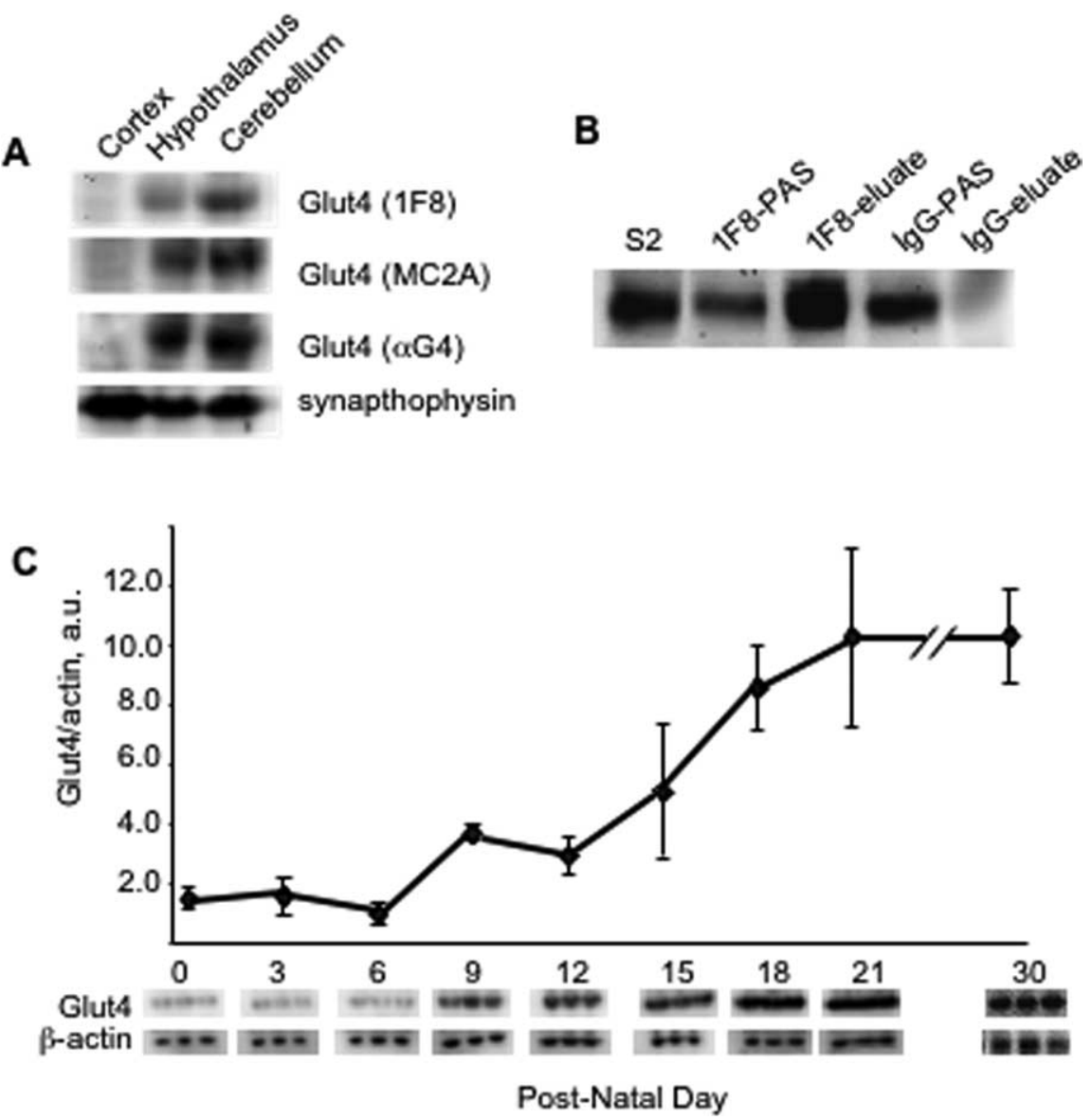

Figure 1. Expression of Glut 4 in the mouse cerebellum. $A$, Dissected brain regions were homogenized in a ball-bearing homogenizer and centrifuged at $1000 \times g$ for 5 min to obtain postnuclear supernatant, which was then analyzed by Western blotting with three different antibodies against Glut 4 (40 $\mu \mathrm{g}$ per lane). B, Triton X-100 and $\mathrm{NaCl}$ were added to $\mathrm{S} 2$ obtained from adult mouse cerebellum to final concentrations of $1 \%$ and $0.5 \mathrm{M}$, respectively, and immunoprecipitation was performed with either 1F8-coupled or IgG-coupled beads as described in Materials and Methods. The beads were washed and eluted with SDS-containing Laemmli sample buffer. The panel shows Western blot of the starting material $(S 2,30 \mu \mathrm{g})$, postadsorptive supernatant (PAS) $(30 \mu \mathrm{g})$, and eluate stained with the polyclonal antibody MC2A against Glut4. C, Cerebella were dissected on the indicated days and total homogenates were analyzed by Western blotting. Glut 4 and actin signals were quantified using the KODAK 1D Image Analysis Software (Eastman Kodak), and normalized data were analyzed using Student'st test. The graph shows mean values \pm SD of three independent experiments. The panels below show the result of a representative experiment.

Cy2-conjugated donkey anti-goat IgG (Jackson ImmunoResearch) at 1:250 dilution. Coverslips were mounted on slides using the SlowFadeLight Antifade kit (Invitrogen). Staining was examined by fluorescence microscopy (Axiovert 200M; Zeiss) or laser scanning fluorescence confocal microscopy (LSM 510 Axiovert 100M; Zeiss).

Gel electrophoresis and immunoblotting. Protein samples were subjected to SDS-PAGE according to Laemmli (1970) and transferred to polyvinylidene difluoride membranes in $25 \mathrm{~mm}$ Tris, $192 \mathrm{~mm}$ glycine. Membranes were blocked with $10 \%$ nonfat dry milk in PBS, $0.05 \%$ Tween 20 and probed with antibodies (1:1000) followed by corresponding horseradish peroxidase-labeled secondary antibodies (1:1000). Blots were developed with ECL reagent (PerkinElmer Life Sciences) and exposed in Eastman Kodak Co. 440 Image Station. Data analysis was performed with Kodak 1D image analysis software.

Acute exercise and positron emission tomography. A small animal positron emission tomography (PET) scanner with a full-width at halfmaximum resolution of $1.8 \mathrm{~mm}$ was used. Individual mice were exercised by running in a treadmill for $2 \mathrm{~h}$ or left to rest without food for $2 \mathrm{~h}$ and anesthetized immediately after each session with continuous $2 \%$ Isoflurene inhalation. All animal protocols were approved by the Institutional Animal Care and Usage Committee. Tail veins were catheterized and blood glucose was measured as control for CSF endogenous glucose levels. After positioning in the scanner, an attenuation data set was ob- tained. Animals were then injected with 200 $\mu \mathrm{Ci}$ of ${ }^{18}$ fluoro-2-deoxyglucose $\left({ }^{18} \mathrm{FDG}\right)$ through the tail vein and scanned for $60 \mathrm{~min}$. Mean ${ }^{18}$ FDG accumulation was calculated for cerebellum and striatum from the last $40 \mathrm{~min}$ of the experiment when ${ }^{18} \mathrm{FDG}$ accumulation reach the plateau. Difference in ${ }^{18}$ FDG accumulation between cerebellum and striatum (left and right) was calculated for individual animals using a Student's $t$ test.

Long-term exercise. CD-1 mice (25 d old) (Charles River Laboratories) were housed under standard lighting ( $12 \mathrm{~h}$ light, $12 \mathrm{~h}$ dark cycle), temperature $\left(22-23^{\circ} \mathrm{C}\right)$, and humidity $(50-60 \%)$ conditions. Food and water were available ad libitum. All mice were acclimated to treadmill running by three $15 \mathrm{~min}$ sessions per day for $2 \mathrm{~d}$. During experimental sessions, a group of 5 mice was confined in treadmills for $2 \mathrm{~h}$ per day for five consecutive days and a control group was left to rest. Immediately after the last session, all mice were killed by $\mathrm{CO}_{2}$ inhalation followed by cervical dislocation. Gastrocnemius muscle and cerebellum were isolated and subjected to biochemical analysis.

\section{Results}

Glut4 is expressed in the granular layer of the mouse cerebellum at a high level

To identify brain regions with the highest content of Glut4, we dissected cortex, hypothalami and cerebella from adult mice, and analyzed Glut4 expression in postnuclear supernatants prepared from these tissues by Western blotting using three different antibodies against Glut4 (Fig. 1A). We found that Glut4 was predominantly expressed in the adult cerebellum (see also (Vannucci et al., 2000), and, to a slightly lesser extent, in the hypothalamus (Fig. $1 A)$. Based on these results, we chose cerebella for the isolation and characterization of the Glut4-containing compartment(s) in neurons. Although immunohistochemical staining revealed the presence of Glut4-positive neurons and nuclei in other brain areas as well (El Messari et al., 1998), the overall levels of Glut4 expression there may or may not be sufficient for the biochemical analysis; therefore, for all following experiments we used cerebella from adult rodents.

Specificity of Glut4 detection in the samples was confirmed with the help of the commercially available antibody C-20 (Santa Cruz, CA) and two other anti-Glut4 polyclonal antibodies raised in sheep and goat (kind gift from Dr. Birnbaum) (data not shown). Additional control experiments showed that the predominant brain glucose transporter Glut3 did not interfere with the detection of Glut4 (data not shown). Furthermore, the $\sim 48$ $\mathrm{kDa}$ protein immunoprecipitated from the cerebellar extract with the help of the monoclonal $1 \mathrm{~F} 8$ antibody was specifically recognized by the polyclonal anti-Glut 4 antibody $\alpha \mathrm{G} 4$ (Fig. $1 B$ ) which strongly suggests that this protein is indeed Glut4. The developmental pattern of Glut4 expression in the cerebellum (Fig. 1C) is reminiscent of its expression in skeletal muscle where Glut4 levels reach the maximum on day 20 (Santalucía et al., 1992). Interestingly, the transcription factor MEF-2 that is re- 
sponsible for Glut4 expression in skeletal muscle (Olson and Knight, 2003) is essential for the survival of Glut4-expressing granule neurons of the cerebellum (Gaudilliere et al., 2002).

In agreement with several previous studies (El Messari et al., 1998; Vannucci et al., 1998; Choeiri et al., 2002), immunohistochemical staining of cerebellar sections showed that Glut4 was localized primarily in the granular layer of the cerebellum and was virtually absent from the molecular layer (Fig. 2A). In subsequent experiments, we isolated cerebellar neurons from $\mathrm{P} 7$ mice and cultured them for $7 \mathrm{~d}$ in vitro. The PCR analysis confirmed the presence of Glut4 mRNA in cultured neurons (supplemental Figs. S1 and S2, available at www.jneurosci.org as supplemental material). Using confocal immunofluorescence microscopy, we found that Glut4 was expressed in the same cells as the neuronal marker protein synaptophysin (Fig. $3 A, B$; supplemental Fig. S3, available at www.jneurosci.org as supplemental material). At the same time, the intracellular localization of Glut 4 and synaptophysin in neurons is apparently different with Glut4 being localized primarily in the cell body (Fig. 3B).

\section{Biochemical characterization of the Glut4-containing compartment in neurons}

To assess the subcellular compartmentalization of Glut 4 in the cerebellar neurons, we applied the fractionation protocol previously used for adipocytes (Kupriyanova et al., 2002) to mouse cerebellum samples and found that a significant fraction of Glut4 resided in the $27,000 \times g$ supernatant, i.e., in the vesicular fraction that contains small synaptic vesicles, or SSVs. We then separated this fraction in the linear sucrose velocity gradient and found that Glut4 did not reside in SSVs marked by the presence of synaptophysin but, rather, in a different and a heavier vesicular population (Fig. 4A) with the sedimentation coefficient identical to "classical" GSVs (Kandror et al., 1995). IRAP and sortilin, the two major protein components of the GSVs from fat and muscle, cosedimented with Glut4 (Fig. 4A) suggesting that these three proteins colocalize in the same vesicular compartment. Equilibrium density centrifugation of cerebellar extracts supports this notion and further shows that, in cerebellar neurons, Glut4-vesicles represent a distinct compartment separate from SSVs (Fig. 4B). Note, that the buoyant density of the GSVs is lower than that of SSVs which is consistent with the observation that the latter have much higher protein to lipid ratio (Sleeman et al., 1998; Kupriyanova et rabbit lgG (lgGr).

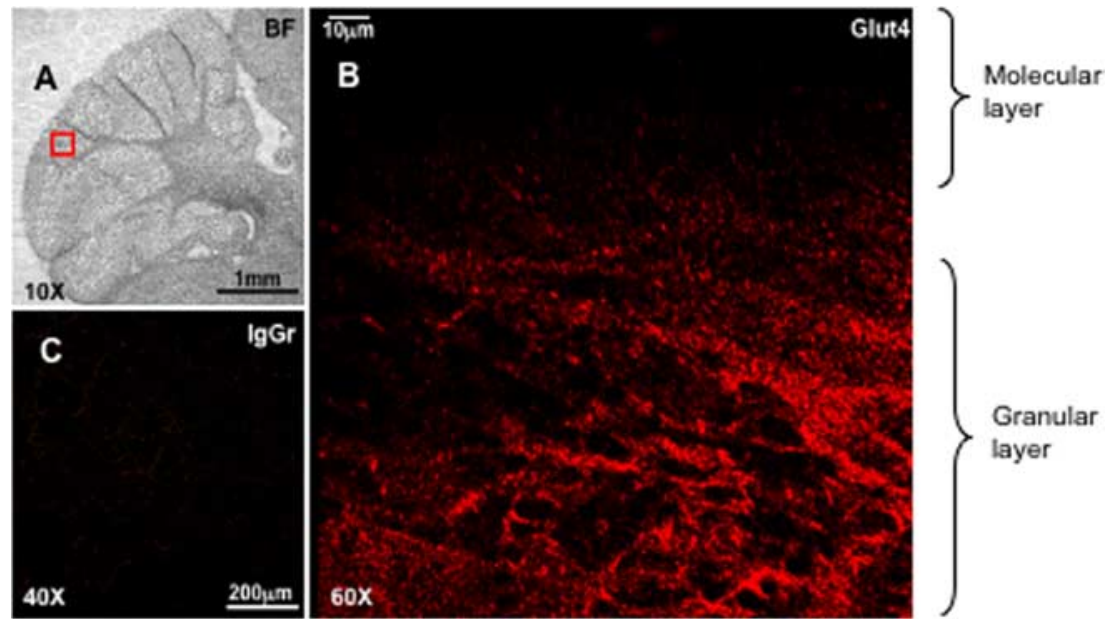

Figure 2. Immunohistochemical staining of the thin sections of mouse cerebellum. $A$, Bright field. The red quadrangle indicates the area shown in $\boldsymbol{B}$ and $\boldsymbol{C}$ under higher magnification. $\boldsymbol{B}$, Staining with MC2A antibody (Glut4). $\boldsymbol{C}$, Control staining with
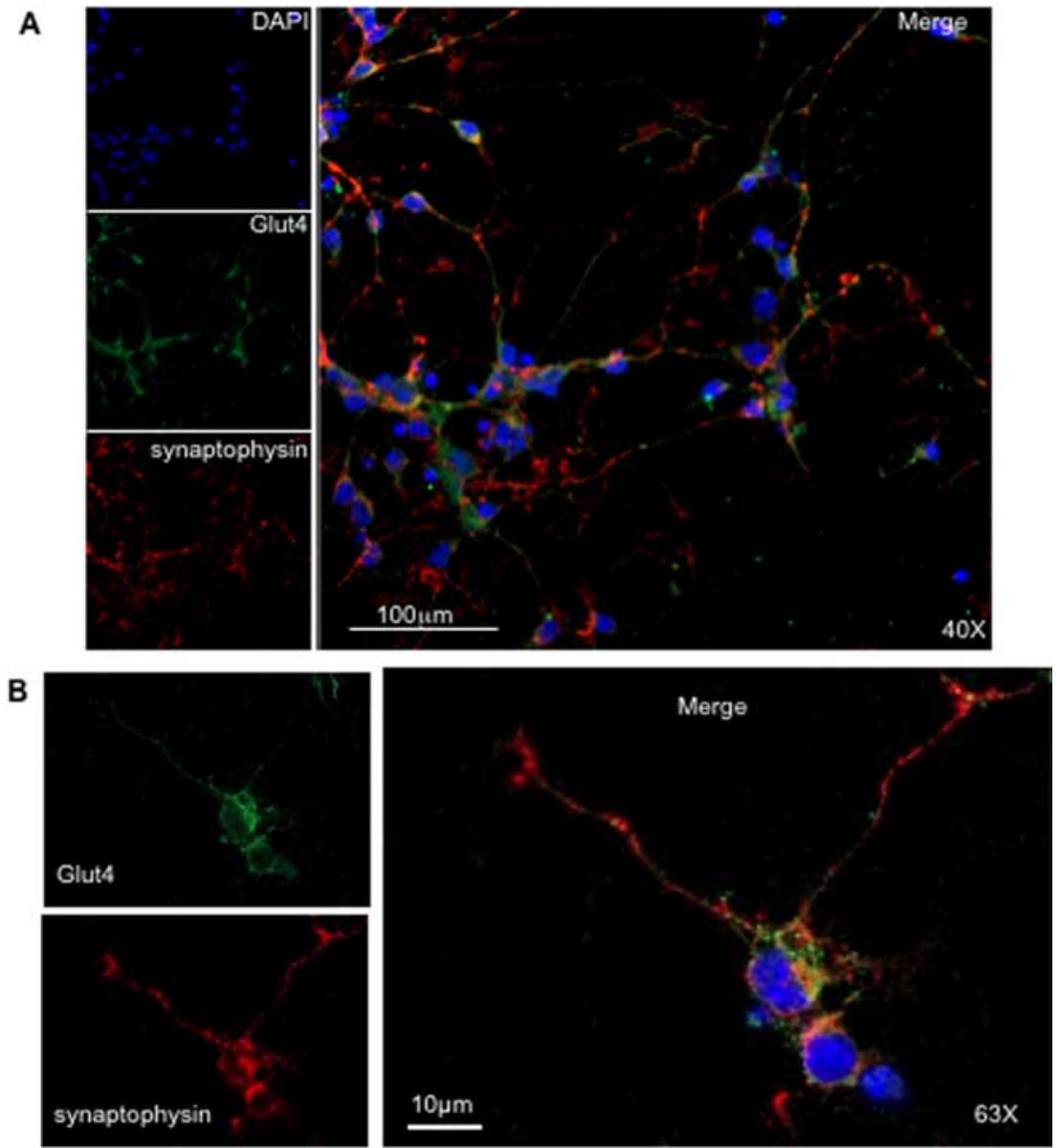

Figure 3. Localization of Glut4 and synaptophysin in cerebellar neurons. Primary cultures of cerebellar neurons were serum starved for $2 \mathrm{~h}$. Cells were stained with the polyclonal antibody MC2A against Glut4 and a monoclonal antibody against synaptophysin followed by Alexa488-conjugated donkey anti-rabbit and Cy3-conjugated donkey anti-mouse antibodies. The figure demonstrates two different panels at $40 \times(\boldsymbol{A})$ and $63 \times(\boldsymbol{B})$ magnification. A low magnification field and nonspecific controls are shown in supplemental Fig. S3 (available at www.jneurosci.org as supplemental material).

al., 2002; Carvalho et al., 2004; Takamori et al., 2006). Finally, immunoadsorption of vesicles from cerebellar extracts with the anti-Glut4 monoclonal antibody 1F8 demonstrated that at least $50 \%$ of total IRAP and sortilin present in the vesicular fraction S2 

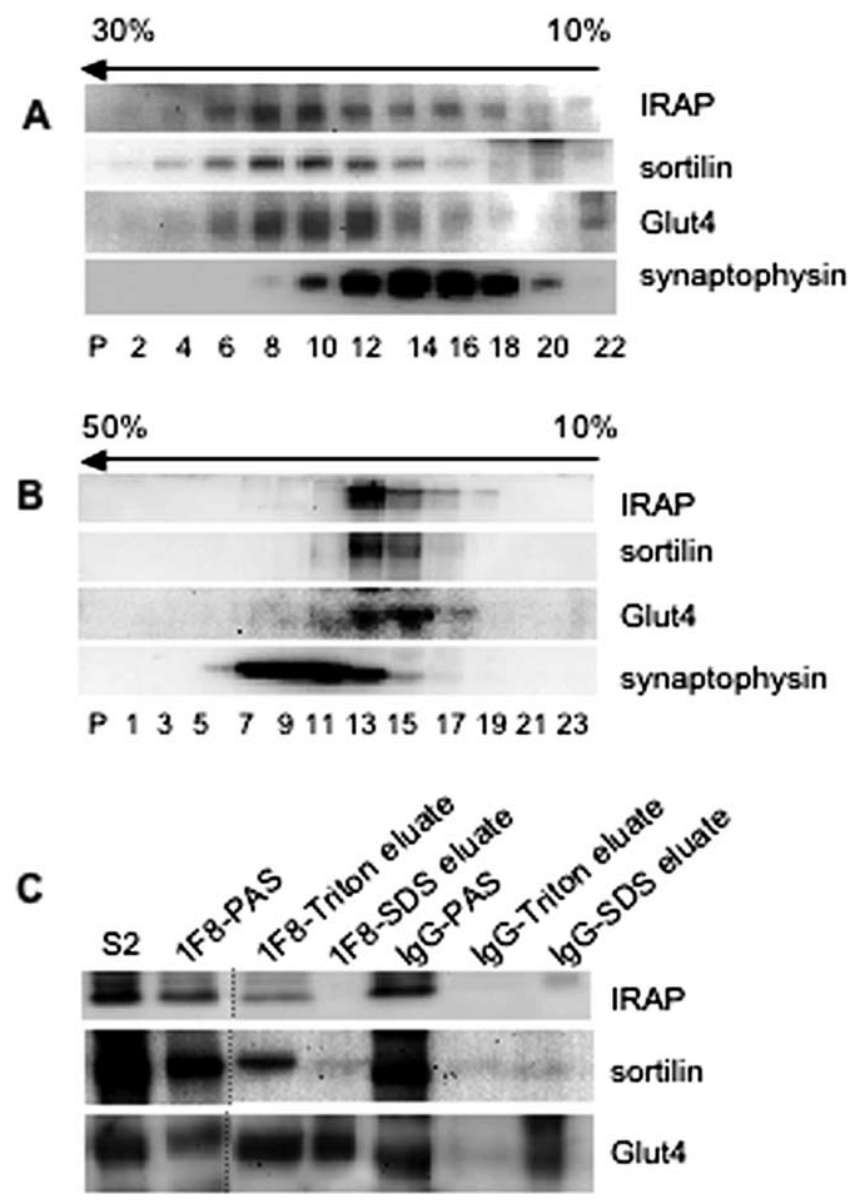

Figure 4. Glut4 in the cerebellum is localized in the GSV-like vesicles. $\boldsymbol{A}$, High speed supernatant from mouse cerebellum was centrifuged in a linear $10-30 \%$ sucrose gradient for $1 \mathrm{~h}$ at $48,0000 \mathrm{rpm}$ in a Beckman Coulter SW55 rotor. The pellet of this centrifugation (P) was analyzed along with gradient fractions by Western blotting. The arrow indicates the direction of sedimentation. $\boldsymbol{B}$, High speed supernatant from mouse cerebellum was centrifuged in an equilibrium density $10-50 \%$ sucrose gradient for $16 \mathrm{~h}$ at $48,0000 \mathrm{rpm}$ in a Beckman Coulter SW50.1 rotor. C, Glut4-containing vesicles were immunoadsorbed from $\$ 2$ prepared from mouse cerebellum in the presence of $0.5 \mathrm{~m} \mathrm{NaCl}$ with 1F8- and nonspecific lgG-coupled beads. Bound material was subsequently eluted with $1 \%$ Triton and Laemmli sample buffer (SDS), and analyzed by Western blotting along with the starting material $(\$ 2,30 \mu \mathrm{g})$ and postadsorptive supernatant (PAS) (30 $\mu \mathrm{g}$ ). Dotted lines indicate that intervening lanes have been spliced out.

colocalized with Glut4 in the same vesicular population (Fig. 4C). Note, that we eluted immunoadsorbed material in two steps, first with $1 \%$ Triton X-100 and then with SDS-containing Laemmli sample buffer. Triton elutes IRAP, sortilin, and a fraction of Glut4, i.e., vesicular proteins that do not bind to the antibody directly. SDS elutes those Glut4 molecules that directly interact with 1F8 antibody. Thus, results of the biochemical fractionation and immunoadsorption collectively suggest that cerebellar neurons have a vesicular compartment analogous to the GSVs.

In cerebellar neurons, Glut 4 is translocated to the plasma membrane in response to insulin stimulation

To address the question of whether neuronal Glut 4 can be translocated to the plasma membrane, we used the primary culture of cerebellar neurons and found that endogenous Glut4 was redistributed from the perinuclear region to the plasma membrane in response to insulin stimulation (Fig. 5A). Measurements of ${ }^{3} \mathrm{H}-$ 2-deoxy-D-glucose uptake showed that translocation of Glut4 was accompanied by an increase in glucose transport which took place in a wortmannin- and indinavir-sensitive manner (Fig. 5B). Because indinavir is a specific inhibitor of Glut4 (Murata et al., 2002), this result, together with the immunofluorescence staining data, strongly suggests that the increase in insulin-stimulated glucose uptake in cultured neurons is mediated by Glut4. In agreement with our results, it was recently shown that insulin may induce plasma membrane translocation of Glut 4 in the SH-SY5Y neuroblastoma cell line (Benomar et al., 2006) and in rat hippocampus (Piroli et al., 2007).

\section{In the cerebellum, Glut4-vesicles translocate to the plasma membrane in response to physical exercise}

In skeletal muscle, GSVs are translocated to the plasma membrane in response to exercise, although the signaling mechanism(s) involved in this process still remain controversial (Rose and Richter, 2005). Given that cerebellum plays a major role in the coordination of motor activity of skeletal muscle, we decided to test whether physical exercise causes translocation of Glut4 in the cerebellum. Mice were exercised by running in a treadmill for $2 \mathrm{~h}$, and glucose uptake in the cerebellum of exercised and nonexercised mice was measured by ${ }^{18}$ fluoro-2-deoxyglucose positron emission tomography. As is shown in Figure $6 \mathrm{~A}$, acute exercise increases accumulation of ${ }^{18} \mathrm{FDG}$ in the cerebellum by $20-25 \%$ ( $p=0.008, n=4$ per group) in comparison to striatum, a brain area in which expression of Glut 4 is virtually undetectable by Western analysis (supplemental Fig. S4, available at www. jneurosci.org as supplemental material). This observation is consistent with earlier results of Vissing et al. who demonstrated that exercise stimulated total cerebrum glucose utilization in rats (Vissing et al., 1996). Another report, however, showed decreased cerebellum glucose uptake during high-intensity exercise associated with massive lactate production in humans (Kemppainen et al., 2005). Because lactate can also be used by the brain to compensate for energy expenditures during high-intensity exercise, it is not surprising that lactate partially reduces glucose consumption and uptake. At the same time, low-intensity exercise may have a stimulatory effect on glucose uptake in the cerebellum (Kemppainen et al., 2005).

To determine whether physical exercise causes translocation of Glut4-vesicles in the cerebellum, we obtained cerebellar extracts from exercised and nonexercised animals and fractionated them in sucrose gradients. Sedimentational analysis (Fig. 6B) showed that exercise significantly decreased the amount of intracellular Glut4-vesicles but has no visible effect on small synaptic vesicles (Fig. $6 B$, note no change in the synaptophysin signal). At the same time, exercise increases the amount of Glut 4 by twofold $(p<0.001, n=5$ per group) in the plasma membrane fraction isolated from cerebellar neurons (Fig. 6C; supplemental Fig. S5, available at www.jneurosci.org as supplemental material). These results collectively suggest that acute physical exercise may induce translocation of Glut4-vesicles to the plasma membrane and increase glucose uptake in the mouse cerebellum.

As activation of AMPK may play an important role in contraction-stimulated translocation of Glut4-vesicles in skeletal muscle (Fujii et al., 2006), we decided to determine whether physical exercise causes activation of AMPK in the cerebellum as well. Indeed, we found that exercise increases phosphorylation of AMPK by twofold ( $p=0.03, n=5$ per group) and that of its substrate, acetyl CoA carboxylase, by twofold ( $p=0.016, n=5$ per group) in the cerebellum (Fig. $6 D$ ). 
Chronic exercise stimulates expression of Glut4 in mouse cerebellum

It was shown previously that physical exercise increased Glut4 levels in skeletal muscle (for review, see Dohm, 2002; Holloszy, 2005). We confirmed these reports by showing that running in a treadmill for $2 \mathrm{~h}$ per day for 5 consecutive days increased Glut 4 content in the mouse gastrocnemius muscle $\sim 2$-fold $(p=0.01$ ) (Fig. 7). Interestingly, Glut4 levels in the cerebellum of exercised mice were also significantly increased $(\sim 2.5$-fold, $p=$ 0.003 ). This observation is not necessarily consistent with the earlier report by Vannucci et al. who have found that physical exercise may actually decrease Glut4 levels in rat cerebellum (Vannucci et al., 1998). This inconsistency may be explained by interspecies differences as well as by technical variations in the preparations of samples. In particular, Vannucci et al. analyzed the membrane fraction obtained by centrifugation at $150,000 \times g$ for $20 \mathrm{~min}$ (Vannucci et al., 1998) which may not be sufficient to pellet small Glut4-vesicles. In our study, we used total homogenates of the cerebellum (Fig. 7). In any case, our results are consistent with the idea that Glut4 in cerebellar neurons and in skeletal muscle is regulated in a similar manner. This may allow for a better coordination of glucose uptake between these tissues.

\section{Discussion}

The GSVs along with SSVs represent well characterized types of intracellular transport vesicles. However, an unresolved problem that has been attracting attention of many researchers for $>10$ years remains whether or not the GSVs and SSVs represent conceptually similar vesicular compartments. The fact that the GSVs and SSVs share several common proteins, such as VAMP2 and SCAMPs, seems to support the idea that these vesicles may represent similar types of compartments formed in different specialized cells. Several research groups (Hudson et al., 1993; Herman et al., 1994; Thorens and Roth, 1996) including ours (Thoidis and Kandror, 2001) attempted to address this question by force-expressing Glut 4 in neuronal cell lines. Others tried to express synaptic proteins in different non-neuronal cells (Johnston et al., 1989; Cameron et al., 1991; Linstedt and Kelly, 1991; Feany et al., 1993; Leube et al., 1994; Belfort et al., 2005). Results of these studies have been somewhat controversial, although several reports do point out to the existence of a distinct type of the GSV-like vesicles in neuronal cells (Herman et al., 1994; Thorens and Roth, 1996; Thoidis and Kandror, 2001). However, the best way to answer this question is to explore the intracellular compartmentalization of Glut4 and/or other GSV proteins endogenously expressed in neurons.

It has been known for $>10$ years that some neurons in the CNS express Glut4, although it has not been clear whether or not Glut4 in the brain is sufficiently abundant for biochemical anal- ysis. We have identified cerebellum as the brain region with high Glut4 content (Fig. 1A; supplemental Fig. S1, available at www. jneurosci.org as supplemental material) and could, therefore, take advantage of the well established methods of the biochemical fractionation used previously for the isolation and characterization of SSVs and GSVs. Our results show that, in cerebellum neurons, Glut4 is not localized in SSVs but rather is present in a different vesicular population that coexists with SSV in the same cells. Interestingly, neuronal Glut4-containing vesicles have the sedimentation coefficient and buoyant density similar to the GSVs from fat and skeletal muscle. In addition, the two proteins colocalized with Glut4 in the GSVs of peripheral insulin-sensitive tissues, IRAP and sortilin, are present in neuronal Glut4containing vesicles as well, suggesting that the mechanism of GSV biogenesis is not tissue-specific. Note, however, that the overall distribution of IRAP and sortilin in different mammalian tissues (Keller et al., 1995; Petersen et al., 1997) as well as brain regions (El Messari et al., 1998; Fernando et al., 2005, 2008) does not necessarily mimic that of Glut4 suggesting that these proteins 
A
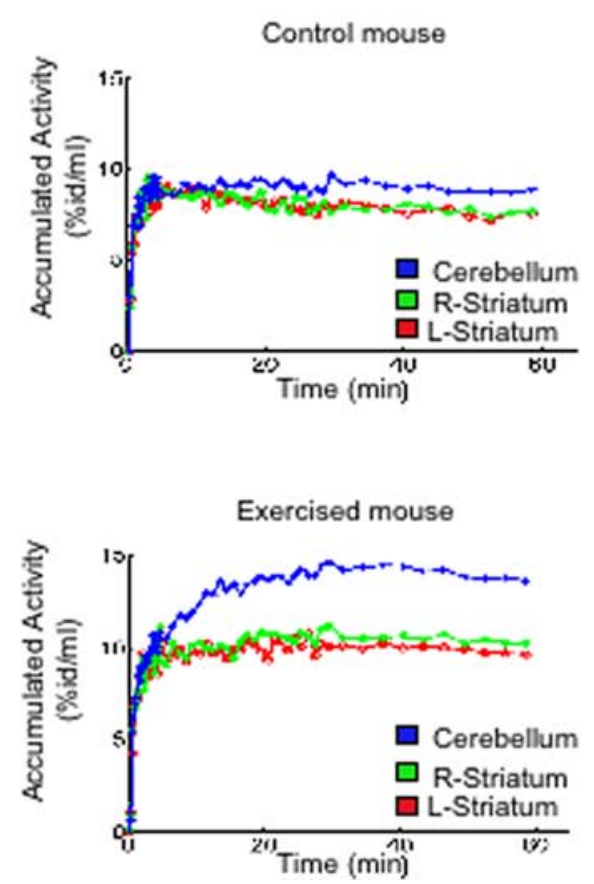
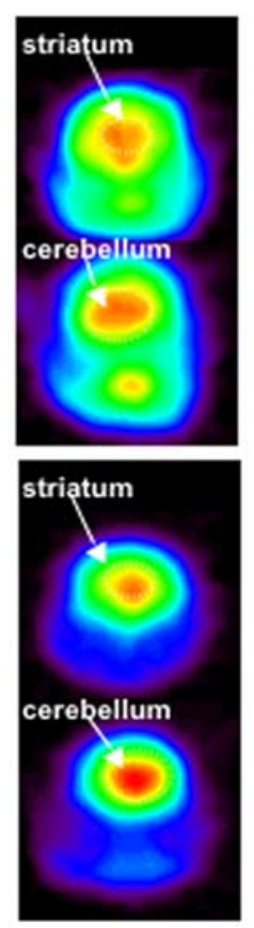

B
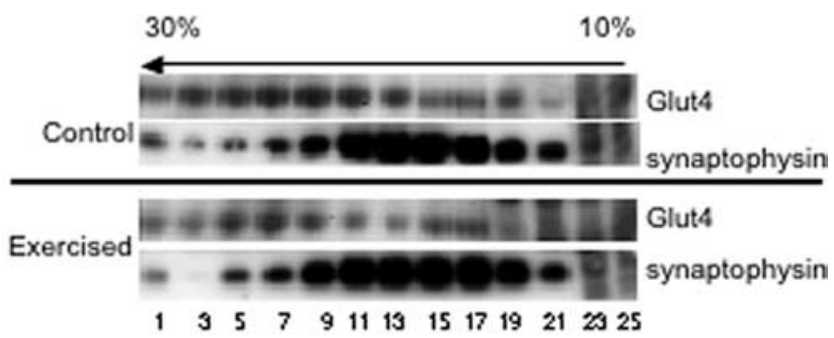

C

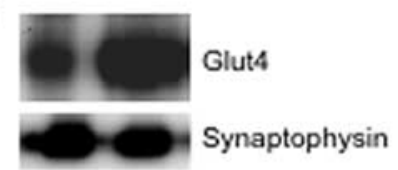

Control Exercised

D

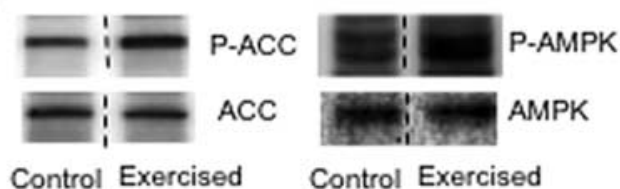

Figure 6. Physical exercise stimulates glucose uptake in mouse cerebellum. $A$, Mice were exercised or left to rest for $2 \mathrm{~h}$, anesthetized, and subjected to the PET scan analysis. The left panels show ${ }^{18} \mathrm{FDG}$ accumulation in the cerebellum and in the striatum (L, left; $R$, right) for representative animals. The right panels show coronal PET images of ${ }^{18} \mathrm{FDG}$ accumulation (sum of frames for the last $40 \mathrm{~min}$ of the procedure when the accumulation reaches the plateau) in the cerebellum and striatum of the representative animals. Mean ${ }^{18} \mathrm{FDG}$ accumulation in the cerebellum and striatum was calculated for the last 40 min of the procedure. The percentage difference between the mean ${ }^{18} \mathrm{FDG}$ accumulation between cerebellum and striatum was calculated using Student's $t$ test $(n=4)$. $B$, High speed supernatants from cerebella of exercised and control mice were fractionated by sucrose gradient centrifugation as described in the legend to Figure $4 A$, and gradient fractions were analyzed by Western blotting. C, Plasma membrane fraction was isolated from cerebella of exercised and control mice as described in Materials and Methods and analyzed by Western blotting. Additional controls are shown in supplemental Fig. S5, available at www.jneurosci.org as supplemental material. Dotted lines indicate that intervening lanes have been spliced out. $\boldsymbol{D}$, Postnuclear supernatant was prepared from cerebella of exercised or control animals and analyzed by Western blotting.

\section{Cerebellum}

Control

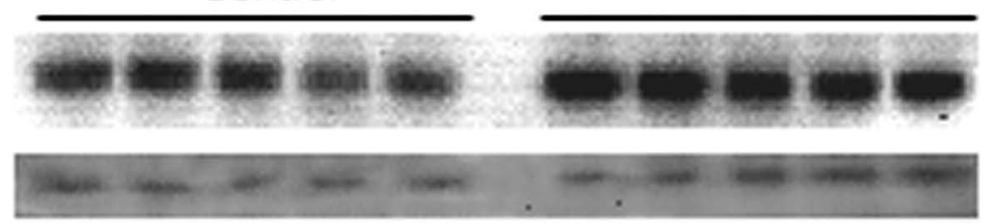

\section{Gastrocnemius}

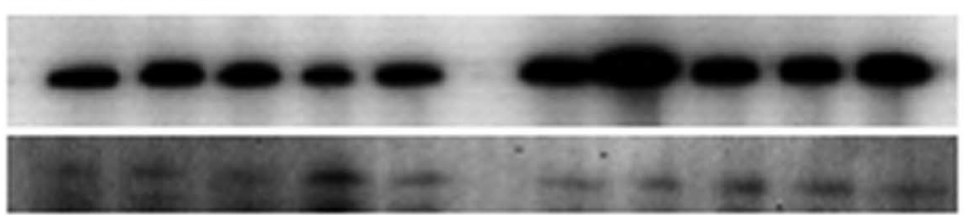

Figure 7. Glut4 content in the cerebellum is increased by physical exercise. Mice (5 per group) were either exercised by running in a treadmill for $2 \mathrm{~h}$ per day for 5 consecutive days, or left to rest in cages as control. Gastrocnemius muscle and cerebella were dissected, homogenized and total homogenates were analyzed by Western blotting. A representative result of three independent experiments is shown.

may have other biological functions not related to regulated glucose uptake. In particular, in the cerebellum, IRAP is highly expressed in Purkinje cells (Fernando et al., 2008) that have undetectable to low levels of Glut4 (Fig. 2) (El Messari et al., 1998; Vannucci et al., 1998). Nonetheless, if IRAP and Glut 4 are coexpressed in the same cell (either neuronal or non-neuronal) both proteins demonstrate a high level of colocalization in small vesi-

\section{Glut4}

actin

\section{Glut4}

actin cles (Kandror et al., 1995; Thoidis and Kandror, 2001; Fernando et al., 2008). Interestingly, Glut4-containing vesicles from the cerebellum neurons are translocated to the plasma membrane in response to insulin stimulation and exercise (Figs. 5, 6) suggesting that neurons possess a novel type of a translocation-competent vesicular compartment.

What could be the biological functions of such a compartment in neurons? We suggest that Glut4-mediated glucose uptake in the brain may provide metabolic fuel for energy-consuming synaptic activity. Indeed, physical exercise is accompanied by elevated synaptic activity of cerebellar neurons that control locomotor muscles; therefore, glucose transport into these neurons needs to be acutely increased to compensate for excess energy demands. In the long run, physical exercise is known to improve cognition and to have a neuroprotective role (Hillman et al., 2008). These long-term effects of exercise may at least in part be explained, by the increase of Glut4 protein expression in neurons (Fig. 7). This increase should lead to better nutrient supply and have a positive effect on the survival and functioning of neurons.

It is also possible that insulin-regulated glucose uptake in the 
brain plays an important role in the control of whole body energy homeostasis and glucose metabolism (Schulingkamp et al., 2000; Schwartz and Porte, 2005; Biddinger and Kahn, 2006; Herman and Kahn, 2006; Myers, 2006). It has been suggested that impaired energy and glucose homeostasis in obesity and diabetes is caused, at least to some degree, by malfunctioning of glucosesensing neurons in the brain (Levin et al., 2002, 2004; Routh, 2002; McEwen and Reagan, 2004; Herman and Kahn, 2006; Parton et al., 2007). Although these neurons are located mainly in the hypothalamus that has not been analyzed in this study, hypothalamus (and, in particular, the arcuate nucleus) has high Glut4 content (Fig. 1A) (Choeiri et al., 2002; Komori et al., 2005). It is feasible, therefore, that Glut 4 in the hypothalamus is also compartmentalized in the vesicles similar to those present in the cerebellum, and that Glut4-mediated glucose uptake in the hypothalamus may represent an essential part of glucose sensing and integration of metabolic and hormone signals. Future studies should determine the role of neuronal Glut4 in regulation of metabolism.

\section{References}

Alquier T, Leloup C, Arnaud E, Magnan C, Pénicaud L (2001) Altered Glut4 mRNA levels in specific brain areas of hyperglycemic-hyperinsulinemic rats. Neurosci Lett 308:75-78.

Apelt J, Mehlhorn G, Schliebs R (1999) Insulin-sensitive GLUT4 glucose transporters are colocalized with GLUT3-expressing cells and demonstrate a chemically distinct neuron-specific localization in rat brain. J Neurosci Res 57:693-705.

Belfort GM, Bakirtzi K, Kandror KV (2005) Cellugyrin induces biogenesis of synaptic-like microvesicles in PC12 cells. J Biol Chem 280:7262-7272.

Benomar Y, Naour N, Aubourg A, Bailleux V, Gertler A, Djiane J, GuerreMillo M, Taouis M (2006) Insulin and leptin induce Glut4 plasma membrane translocation and glucose uptake in a human neuronal cell line by a phosphatidylinositol 3-kinase-dependent mechanism. Endocrinology 147:2550-2556.

Biddinger SB, Kahn CR (2006) From mice to men: insights into the insulin resistance syndromes. Annu Rev Physiol 68:123-158.

Cain CC, Trimble WS, Lienhard GE (1992) Members of the VAMP family of synaptic vesicle proteins are components of glucose transportercontaining vesicles from rat adipocytes. J Biol Chem 267:11681-11684.

Cameron PL, Südhof TC, Jahn R, DeCamilli P (1991) Colocalization of synaptophysin with transferrin receptors: implications for synaptic vesicles biogenesis. J Cell Biol 115:151-164.

Carvalho E, Schellhorn SE, Zabolotny JM, Martin S, Tozzo E, Peroni OD, Houseknecht KL, Mundt A, James DE, Kahn BB (2004) GLUT4 overexpression or deficiency in adipocytes of transgenic mice alters the composition of GLUT4 vesicles and the subcellular localization of GLUT4 and insulin-responsive aminopeptidase. J Biol Chem 279:21598-21605.

Choeiri C, Staines W, Messier C (2002) Immunohistochemical localization and quantification of glucose transporters in the mouse brain. Neuroscience 111:19-34.

Dohm GL (2002) Invited review: regulation of skeletal muscle GLUT-4 expression by exercise. J Appl Physiol 93:782-787.

El Messari S, Leloup C, Quignon M, Brisorgueil MJ, Penicaud L, Arluison M (1998) Immunocytochemical localization of the insulin-responsive glucose transporter 4 (Glut4) in the rat central nervous system. J Comp Neurol 399:492-512.

Feany MB, Yee AG, Delvy ML, Buckley KM (1993) The synaptic vesicle proteins SV2, synaptotagmin and synaptophysin are sorted to separate cellular compartments in CHO fibroblasts. J Cell Biol 123:575-584.

Fernando RN, Larm J, Albiston AL, Chai SY (2005) Distribution and cellular localization of insulin-regulated aminopeptidase in the rat central nervous system. J Comp Neurol 487:372-390.

Fernando RN, Luff SE, Albiston AL, Chai SY (2007) Sub-cellular localization of insulin-regulated membrane aminopeptidase, IRAP to vesicles in neurons. J Neurochem 102:967-976.

Fernando RN, Albiston AL, Chai SY (2008) The insulin-regulated aminopeptidase IRAP is colocalised with GLUT4 in the mouse hippocampuspotential role in modulation of glucose uptake in neurones? Eur J Neurosci 28:588-598.
Fujii N, Jessen N, Goodyear LJ (2006) AMP-activated protein kinase and the regulation of glucose transport. Am J Physiol Endocrinol Metab 291:E867-877.

Gaudilliere B, Shi Y, Bonni A (2002) RNA interference reveals a requirement for myocyte enhancer factor $2 \mathrm{~A}$ in activity-dependent neuronal survival. J Biol Chem 277:46442-46446.

Herman GA, Bonzelius F, Cieutat AM, Kelly RB (1994) A distinct class of intracellular storage vesicles, identified by expression of the glucose transporter GLUT4. Proc Natl Acad Sci U S A 91:12750-12754.

Herman MA, Kahn BB (2006) Glucose transport and sensing in the maintenance of glucose homeostasis and metabolic harmony. J Clin Invest 116:1767-1775.

Hillman CH, Erickson KI, Kramer AF (2008) Be smart, exercise your heart: exercise effects on brain and cognition. Nat Rev Neurosci 9:58-65.

Holloszy JO (2005) Exercise-induced increase in muscle insulin sensitivity. J Appl Physiol 99:338-343.

Huang S, Czech MP (2007) The GLUT4 glucose transporter. Cell Metab 5:237-252.

Hudson AW, Fingar DC, Seidner GA, Griffiths G, Burke B, Birnbaum. MJ (1993) Targeting of the "insulin-responsive" glucose transporter (GLUT4) to the regulated secretory pathway in PC12 cells. J Cell Biol 122:579-588.

Johnston PA, Cameron PL, Stukenbrok H, Jahn R, De Camilli P, Südhof TC (1989) Synaptophysin is targeted to similar microvesicles in $\mathrm{CHO}$ and PC12 cells. EMBO J 8:2863-2872.

Kandror KV, Yu L, Pilch PF (1994) The major protein of GLUT4containing vesicles, gp160, has aminopeptidase activity. J Biol Chem 269:30777-30780.

Kandror KV, Coderre L, Pushkin AV, Pilch PF (1995) Comparison of GLUT4-containing vesicles from rat fat and muscle tissues- evidence for a unique endosomal compartment. Biochem J 307:383-390.

Keller SR, Scott HM, Mastick CC, Aebersold R, Lienhard GE (1995) Cloning and characterization of a novel insulin-regulated membrane aminopeptidase from Glut4 vesicles. J Biol Chem 270:23612-23618.

Kemppainen J, Aalto S, Fujimoto T, Kalliokoski KK, Långsjö J, Oikonen V, Rinne J, Nuutila P, Knuuti J (2005) High intensity exercise decreases global brain glucose uptake in humans. J Physiol 568:323-332.

Kobayashi M, Nikami H, Morimatsu M, Saito M (1996) Expression and localization of insulin-regulatable glucose transporter (GLUT4) in rat brain. Neurosci Lett 213:103-106.

Komori T, Morikawa Y, Tamura S, Doi A, Nanjo K, Senba E (2005) Subcellular localization of glucose transporter 4 in the hypothalamic arcuate nucleus of ob/ob mice under basal conditions. Brain Res 1049:34-42.

Kupriyanova TA, Kandror V, Kandror KV (2002) Isolation and characterization of the two major intracellular Glut4 storage compartments. J Biol Chem 277:9133-9138.

Laemmli UK (1970) Cleavage of structural proteins during the assembly of the head of bacteriophage T4. Nature 227:680-685.

Larance M, Ramm G, Stöckli J, van Dam EM, Winata S, Wasinger V, Simpson F, Graham M, Junutula JR, Guilhaus M, James DE (2005) Characterization of the role of the Rab GTPase-activating protein AS160 in insulinregulated GLUT4 trafficking. J Biol Chem 280:37803-37813.

Laurie SM, Cain CC, Lienhard GE, Castle JD (1993) The glucose transporter GluT4 and secretory carrier membrane proteins (SCAMPs) colocalize in rat adipocytes and partially segregate during insulin stimulation. J Biol Chem 268:19110-19117.

Leloup C, Arluison M, Kassis N, Lepetit N, Cartier N, Ferré P, Pénicaud L (1996) Discrete brain areas express the insulin-responsive glucose transporter GLUT4. Brain Res Mol Brain Res 38:45-53.

Leube RE, Leimer U, Grund C, Franke WW, Harth N, Wiedenmann B (1994) Sorting of synaptophysin into special vesicles in nonneuroendocrine epithelial cells. J Cell Biol 127:1589-1601.

Levin BE, Dunn-Meynell AA, Routh VH (2002) CNS sensing and regulation of peripheral glucose levels. Int Rev Neurobiol 51:219-258.

Levin BE, Routh VH, Kang L, Sanders NM, Dunn-Meynell AA (2004) Neuronal glucosensing: what do we know after 50 years? Diabetes 53:2521-2528.

Lin BZ, Pilch PF, Kandror KV (1997) Sortilin is a major protein component of Glut4-containing vesicles. J Biol Chem 272:24145-24147.

Linstedt AD, Kelly RB (1991) Synaptophysin is sorted from endocytotic markers in neuroendocrine PC12 cells but not transfected fibroblasts. Neuron 7:309-317. 
Lu T, Pan Y, Kao SY, Li C, Kohane I, Chan J, Yankner BA (2004) Gene regulation and DNA damage in the ageing human brain. Nature 429:883-891.

Mazella J, Zsürger N, Navarro V, Chabry J, Kaghad M, Caput D, Ferrara P, Vita N, Gully D, Maffrand JP, Vincent JP (1998) The 100-kDa neurotensin receptor is gp95/sortilin, a non-G-protein-coupled receptor. J Biol Chem 273:26273-26276.

McCall AL, van Bueren AM, Huang L, Stenbit A, Celnik E, Charron MJ (1997) Forebrain endothelium express Glut4, the insulin-responsive glucose transporter. Brain Res 744:318-326.

McEwen BS, Reagan LP (2004) Glucose transporter expression in the central nervous system: relationship to synaptic function. Eur J Pharmacol 490:13-24.

Morris NJ, Ross SA, Lane WS, Moestrup SK, Petersen CM, Keller SR, Lienhard GE (1998) Sortilin is the major 110-kDa protein in GLUT4 vesicles from adipocytes. J Biol Chem 273:3582-3587.

Murata H, Hruz PW, Mueckler M (2002) Indinavir inhibits the glucose transporter isoform Glut4 at physiologic concentrations. AIDS $16: 859-863$.

Myers MG Jr (2006) Role reversal: brain insulin and liver STAT3. Cell Metab 3:231-232.

Olson AL, Knight JB (2003) Regulation of GLUT4 expression in vivo and in vitro. Front Biosci 8:s401-s409.

Parton LE, Ye CP, Coppari R, Enriori PJ, Choi B, Zhang CY, Xu C, Vianna CR, Balthasar N, Lee CE, Elmquist JK, Cowley MA, Lowell BB (2007) Glucose sensing by POMC neurons regulates glucose homeostasis and is impaired in obesity. Nature 449:228-232.

Petersen CM, Nielsen MS, Nykjaer A, Jacobsen L, Tommerup N, Rasmussen HH, Roigaard H, Gliemann J, Madsen P, Moestrup SK (1997) Molecular identification of a novel candidate sorting receptor purified from human brain by receptor-associated protein affinity chromatography. J Biol Chem 272:3599-3605.

Piroli GG, Grillo CA, Reznikov LR, Adams S, McEwen BS, Charron MJ, Reagan LP (2007) Corticosterone impairs insulin-stimulated translocation of GLUT4 in the rat hippocampus. Neuroendocrinology 85:71-80.

Ploug T, van Deurs B, Ai H, Cushman SW, Ralston E (1998) Analysis of GLUT4 distribution in whole skeletal muscle fibers: identification of distinct storage compartments that are recruited by insulin and muscle contractions. J Cell Biol 142:1429-1446.

Rayner DV, Thomas ME, Trayhurn P (1994) Glucose transporters (GLUTs 1-4) and their mRNAs in regions of the rat brain: insulin-sensitive transporter expression in the cerebellum. Can J Physiol Pharmacol 72:476-479.

Rose AJ, Richter EA (2005) Skeletal muscle glucose uptake during exercise: how is it regulated? Physiology (Bethesda) 20:260-270.
Routh VH (2002) Glucose-sensing neurons: are they physiologically relevant? Physiol Behav 76:403-413.

Santalucía T, Camps M, Castelló A, Muñoz P, Nuel A, Testar X, Palacin M, Zorzano A (1992) Developmental regulation of GLUT-1 (erythroid/ Hep G2) and GLUT-4 (muscle/fat) glucose transporter expression in rat heart, skeletal muscle, and brown adipose tissue. Endocrinology 130:837-846.

Schulingkamp RJ, Pagano TC, Hung D, Raffa RB (2000) Insulin receptors and insulin action in the brain: review and clinical implications. Neurosci Biobehav Rev 24:855-872.

Schwartz MW, Porte D Jr (2005) Diabetes, obesity, and the brain. Science 307:375-379.

Sleeman MW, Donegan NP, Heller-Harrison R, Lane WS, Czech MP (1998) Association of acyl-CoA synthetase-1 with Glut4-containing vesicles. J Biol Chem 273:3132-3135.

Smith RM, Charron MJ, Shah N, Lodish H, Jarett L (1991) Immunoelectron microscopic demonstration of insulin-stimulated translocation of glucose transporters to the plasma membrane of isolated rat adipocytes and masking of the carboxyl-terminal epitope of intracellular GLUT4. Proc Natl Acad Sci U S A 88:6893-6897.

Takamori S, Holt M, Stenius K, Lemke EA, Grønborg M, Riedel D, Urlaub H, Schenck S, Brügger B, Ringler P, Müller SA, Rammner B, Gräter F, Hub JS, De Groot BL, Mieskes G, Moriyama Y, Klingauf J, Grubmüller H, Heuser J, et al. (2006) Molecular anatomy of a trafficking organelle. Cell 127:831-846.

Thoidis G, Kandror KV (2001) A Glut4-vesicle marker protein, insulinresponsive aminopeptidase, is localized in a novel vesicular compartment in PC12 cells. Traffic 2:577-587.

Thoidis G, Kotliar N, Pilch PF (1993) Immunological analysis of GLUT4 enriched vesicles. Identification of novel proteins regulated by insulin and diabetes. J Biol Chem 268:11691-11696.

Thorens B, Roth J (1996) Intracellular targeting of Glut4 in transfected insulinoma cells: evidence for association with constitutively recycling vesicles distinct from synaptophysin and insulin vesicles. J Cell Sci 109:1311-1323.

Vannucci SJ, Koehler-Stec EM, Li K, Reynolds TH, Clark R, Simpson IA (1998) GLUT4 glucose transporter expression in rodent brain: effect of diabetes. Brain Res 797:1-11.

Vannucci SJ, Rutherford T, Wilkie MB, Simpson IA, Lauder JM (2000) Prenatal expression of the GLUT4 glucose transporter in the mouse. Dev Neurosci 22:274-282.

Vissing J, Andersen M, Diemer NH (1996) Exercise-induced changes in local cerebral glucose utilization in the rat. J Cereb Blood Flow Metab 16: $729-736$ 